\title{
Spatial geoecological modeling of the natural- agrarian potential of the region landscapes
}

\author{
Aleksey Osipov ${ }^{1}$, Vladimir Garmanov ${ }^{2}$, Vladimir Bogdanov², Galina Efimova $^{2}$, Boris \\ Zavarin $^{2}$, Viktoriia Pavlova $^{2}$, Ekaterina Uvarova $^{2}$, Vitaly Terleev ${ }^{3,4}$, and Aleksandr \\ Nikonorov ${ }^{5, *}$ \\ ${ }^{1}$ A.F. Mozhaysky's Military-Space Academy, Zhdanovskaya Naberezhnaya, 13, St. Petersburg, \\ 197198, Russian Federation \\ ${ }^{2}$ St.Petersburg State Agrarian University, Peterburgskoe shosse, 2, St. Petersburg-Pushkin, 196601, \\ Russian Federation \\ ${ }^{3}$ Peter the Great St.Petersburg Polytechnic University, Polytechnicheskaya, 29, St. Petersburg, \\ 195251, Russian Federation \\ ${ }^{4}$ Agrophysical Research Institute, Grazhdansky pr., 14, St. Petersburg, 195220, Russian Federation \\ ${ }^{5}$ LLC «Gazprom pererabotka Blagoveshchensk», p. Gazoprovod, p. Sosenskoe, Moscow, 108814, \\ Russian Federation
}

\begin{abstract}
The article describes the scientific and methodological foundations of spatial geoecological modeling of the natural and agricultural potential of the region's landscapes, the theoretical basis of which is the methodology of multiparameter analysis of complex objects, implemented in the form of two methods: summary indicators and randomized summary indicators. The essence of modeling is in mathematical-cartographic spatial analysis in the GIS environment of the favorableness of natural landscapes for environmentally friendly agricultural production. It is based on the principles of consistency, priority of the assessed indicators, continuity, regionality, emergence, scale, visibility of the display of results. During the development of the scientific and methodological foundations, the following methods of geographical research were used: ranking the properties of landscapes by their impact on the natural and agricultural potential, building model-classifications for assessing the natural-agricultural potential, convolution of multi-parameter information in conditions of information deficit. The developed method includes six blocks. The method has been tested in the Leningrad Region. The results of approbation do not contradict the data of other researchers obtained for the studied region. The developed method can be applied in land management and territorial planning.
\end{abstract}

\section{Introduction}

At present, the problems of ecologically safe nature management have sharply aggravated, which is associated with the irrational use of natural resources. Therefore, geography is dominated by research aimed at developing the theory and practice of forming ecologically safe natural-anthropogenic geosystems. One of the most important areas of this

\footnotetext{
*Corresponding author: coolhabit@yandex.ru
} 
activity is geoecological modeling [3, 10, 14, 22]. The modeling results make it possible to territorially differentiate anthropogenic loads on landscapes, strictly linking them with a specific geoecological situation $[1,11,12,21,25]$. One of the most relevant objects of geoecological modeling is the natural-agricultural potential, by which the authors understand the ability of natural resources to ensure environmentally sustainable development of agricultural production.

Many works are devoted to the issues of geoecological optimization of landscapes: Volodin et al., 2000; Girardin et al., 2000; Kiryushin, 2005; Nemykin, 2005; Chursin, 2008; Martins Junioretal., 2010; Arefiev, 2011; Kruchinkina, 2011; Lopyrev et al., 2012; Malezieux, 2012; Osipov, 2016; Shishov, 2018, etc. However, to date, this problem has not yet been solved, therefore, landscapes with a high natural and agricultural potential are often used for other types of nature management.

As a result, a problem arose associated with the improvement of the scientific and methodological foundations of geoecological analysis of landscapes during their agricultural development. This article is dedicated to resolving this problem.

The aim of the article was to develop and test a methodology for geoecological modeling of the natural and agricultural potential of the region's landscapes [26-28], by which the authors understand the mathematical-cartographic, spatial analysis in the GIS environment of the favorableness of natural landscapes for environmentally safe agricultural activities [2933].

\section{Materials and methods}

This research is based on the concept of equilibrium nature management $[2,5,7,13,20,23$, 24]. The main tool, which, according to the authors, is geoecological modeling. It allows one to assess the spatial distribution of the studied geoecological processes or phenomena within the studied landscapes and present the results of the assessment in a cartographic form $[4,8$, 9].

The authors propose to carry out geoecological modeling using the methodology of multivariate analysis of complex objects, implemented in the form of two methods: summary indicators [15] and randomized summary indicators [6, 18].

It is proposed to lay the following principles as the basis for geoecological modeling [15]:

1) the principle of consistency. Geoecological modeling should be based on the theory of systems analysis.

2) the principle of taking into account the priority of indicators. When implementing the procedure for geoecological modeling, the degree of influence of each assessed indicator on the suitability of the landscape for agricultural development should be taken into account.

3 ) the principle of continuity. Geoecological modeling should be carried out for the entire study area.

4) the principle of regionality. Geoecological modeling should be focused on the peculiarities of the natural conditions of the studied region.

5 ) the principle of emergence. Geoecological modeling should be based on the totality of the properties of the studied landscapes, and not on individual properties.

7) the principle of scale. Geoecological modeling should ensure consistency between its detail and the area of the study area.

8 ) the principle of visibility of displaying simulation results. The results of geoecological modeling should be displayed in the form of a set of analytical (factorial) and synthetic maps, allowing to make informed decisions on the agricultural use of landscapes.

The created method of spatial geoecological modeling includes six blocks: 1) preparation of source materials for modeling; 2) development of an information model; 3) ranking the properties of landscapes according to their influence on the natural and agricultural potential; 
4) the choice of assessment classes and the construction of qualimetric scales for them; 5) modeling of the natural and agricultural potential of landscapes; 6) creation of synthetic maps of the natural and agricultural potential of landscapes.

First block. At this stage of work, materials that characterize the region under study are collected and studied. In parallel with this, the preparation of the cartographic base is carried out. Topographic maps of scales 1: 50000 - 1: 100000 are used for this task.

The main sources of information about the landscape and soil structure of the study area are materials of landscape and soil surveys.

Information on soil surveys is stored in the State Land Management Data Fund. However, when using these materials, the problem of their coordinate referencing arises. soil maps stored in the fund are created in a conventional coordinate system.

The authors have developed a technology for creating electronic soil maps in the GIS environment based on archived data. Its implementation began with the creation in the GIS "Map 2011" of the frames of the sheets of topographic maps at a scale of 1: 50,000, included in the limits of the study area. Then analog topographic maps were scanned and linked in the GIS "Map 2011". Then the resulting images were converted into the GIS "MapInfo" format and snapped to the corners of the trapezoid frames. Then analog archive soil maps were converted into raster format and linked in GIS "MapInfo" to a topographic map from the image. In conclusion, the accuracy of the created electronic soil maps was determined

Second block. The main purpose of the information model is to establish the data necessary and sufficient for the implementation of the geoecological modeling procedure at the level of conceptual representation.

In the process of building an information model, four reference books are being developed:

1) the rules of geoecological modeling;

2) operations implementing the procedure of geoecological modeling;

3) data necessary to perform operations;

4) connections of operations with data.

The graphical representation of the information model has the form of a tree structure, the principles of construction, which are given in [15].

Third block. When ranking properties, their unnormalized weights are firstly determined, and then the normalized ones.

The method of paired comparisons is used to determine the unnormalized coefficients. The normalized coefficients are calculated by multiplying the unnormalized coefficients of the properties related to each other in the information model [15].

Fourth block. For geoecological modeling of the natural-agrarian potential of landscapes, a five-step scale is used: very low potential - 1 class, low potential - 2 class, medium potential - 3 class, high potential - 4 class, very high potential - 5 class.

It is proposed to lay the approaches used in the creation of classification models as the basis for the construction of qualimetric scales. The work begins with the substantiation of a system of indicators that allow diagnosing the natural and agricultural potential of landscapes. At the same time, the condition should be observed that each of the indicators was necessary, and all indicators together were sufficient to characterize the natural and agricultural potential.

During the scales development, the numerator gives the values of the left and right class boundaries, and the denominator gives their normalized characteristics. The last line contains the integral indicators of the construction rule, which are described in [6].

It is proposed to use functions of the form (1) and (2) [18] to normalize the estimated values of indicators. 


$$
\begin{gathered}
q_{i}=q_{i}\left(x_{i}\right)=\left\{\begin{array}{lr}
0, & x_{i} \leq \min _{i}, \\
\left(\frac{x_{i}-\min _{i}}{\max _{i}-\min _{i}}\right)^{\lambda}, \min _{i}<x_{i} \leq \max _{i}, & x_{i}>\max _{i} \\
1, & x_{i} \leq \min _{i},
\end{array}\right. \\
q_{i}=q_{i}\left(x_{i}\right)=\left\{\begin{array}{lr}
1, & x_{i}>\max _{i} . \\
\left(\frac{\max _{i}-x_{i}}{\max _{i}-\min _{i}}\right)^{\lambda}, \min _{i}<x_{i} \leq \max _{i}, \\
0, &
\end{array}\right.
\end{gathered}
$$

Function (1) is used when increasing $i$-th indicator does not entail a decrease in the natural and agricultural potential. In this case, indicators in which the value is equal to $x_{i}$, does not exceed the level of $\min _{i}$, the minimum value is assigned, and the indicators in which the value is equal to $x_{i}$, surpasses the level of $\max _{i}$, - maximum value.

In practice, as $\min _{i}$ zero, background or maximum permissible value of the indicator is accepted. However, for $\max _{i}$ it is not always advisable to take the max value of $x_{i}$ last class, because it can be big enough. As a result, more than $40 \%$ the entire rating scale can fall into the last class. In this case, as $\max _{i}$ could be used the "regional maximum" or $\max _{i}$ taking into account changes by class of quantity $\Delta x_{i}$.

In functions (1) and (2), the exponent $\lambda$ introduced to take into account the nonlinearity of links. However, in view of the fact that it does not make significant changes to the scale of the integral indicator, it is advisable to take it equal to one.

Non-decreasing function (2) is used when the value of the natural-agricultural potential, assessed by $i$-th indicator, does not increase.

The following dependence is proposed to determine the integral indicators of the normalized characteristics of the boundaries of the classes of the natural-agricultural potential of landscapes:

$$
I=\frac{\sum_{i=1}^{m} q_{i}}{m},
$$

where: $I$ - integral indicator of the normalized characteristic of the class boundary; $q_{i}-$ normalized estimated value of $i$-th indicator; $m$ - number of indicators involved in the assessment.

Fifth block. In a GIS environment, using the "topological overlay" operation, soil plots are linked to agricultural lands. After that, for all tied soil areas, their characteristics are determined. Then, according to dependencies (1) and (2), the normalized values of indicators are calculated, and using relationship (4), weighted values of integral indicators of the natural-agricultural potential of soils.

$$
G_{s}=\sum_{i=1}^{m} q_{i} P_{i},
$$

where: $G_{s}$ - weighted value of the integral indicator of natural and agricultural potential of $s$ th allotment; $P_{j}$ - normalized weight factor of $i$-th indicator.

At the final stage of the implementation of the fifth block, using dependence (5), an integral indicator of its natural and agricultural potential is determined for each landscape. 


$$
L_{j}=\frac{\sum_{s=1}^{n} G_{s j} r_{s}}{R_{j}},
$$

where: $L_{j}$ - integral indicator of natural and agricultural potential of $j$-th landscape; $G_{s j}$ integral indicator of natural and agricultural potential of $s$-th allotment of agricultural land of $j$-th landscape; $r_{s}-$ area of $s$-th allotment; $R_{j}$ - the area of soil allotments within agricultural land of $j$-th landscape.

Sixth block. Electronic synthetic maps of natural and agricultural potentials are created by linking the values of the calculated potentials to the objects of geoecological assessment (soil plots, agricultural lands and landscapes). After that, objects that fall into one class are combined into one area and are displayed with the accepted conventional sign.

\section{Results and discussions}

The developed method was tested on the territory of the Leningrad region. In each type of landscapes located within the region, "key" areas were selected, the most typical for the studied species. They were chosen in such a way that they could be used to characterize the features of the formation of the natural-agricultural potential within the studied type of landscapes. The selection of the key site was carried out in an interactive mode by analyzing the natural components of landscapes that form this species (including relief, soils, vegetation, grounds, moisture conditions) using materials from landscape studies (maps, profiles, descriptions), as well as data from forest management documentation and forest cadaster. Based on the analysis, for each species, the most typical landscapes were identified, within which key areas were selected. A total of 14 "key" sites were selected. For each "key" site in the GIS environment, two cartographic layers were created: 1) agricultural land and 2) soil areas. After that, using the "topological overlay" operation, the summation of these layers was performed, as a result of which the soil plots were tied to agricultural lands.

An information model was developed to assess the natural and agricultural potential of landscapes.

Then, using the approaches described in [15], the ranking of indicators characterizing the natural-agrarian potential of landscapes was carried out, shown on the Fig. 1.

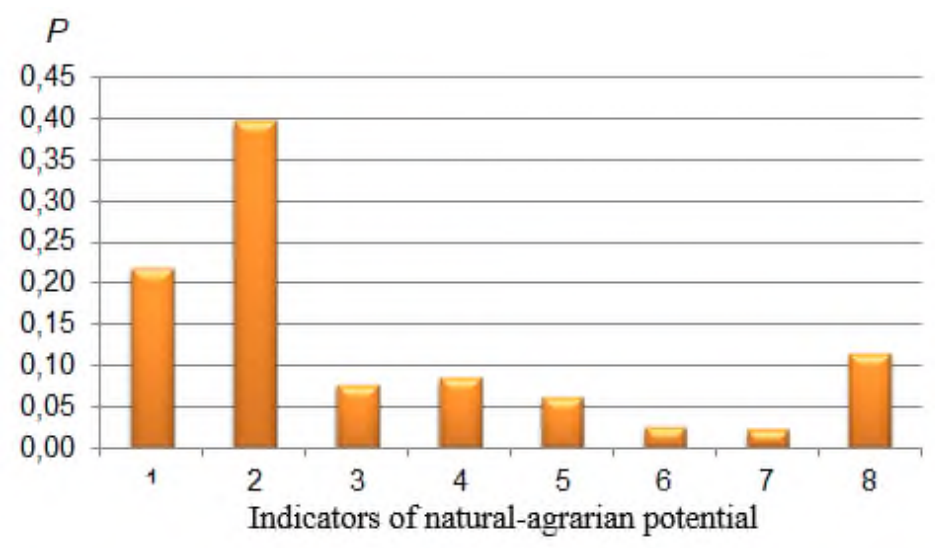

Fig. 1. Results of indicators ranking characterizing the natural and agricultural potential of landscapes. 
Where: 1 - agroclimatic potential; 2 - soil bonitet; 3 - ecological and geochemical potential; 4 - soil washable; 5 - ecosystem diversity; 6 - the density of the hydrographic network; 7 - depth of groundwater; 8 - erosion potential of the relief).

After that, using dependencies (1), (2) and (3), qualimetric scales of classes for assessing the natural-agricultural potential of landscapes were developed (Table 1).

Table 1. The natural-agricultural potential of landscapes were developed.

\begin{tabular}{|c|c|c|c|c|c|c|c|c|}
\hline \multirow{2}{*}{ Indicator } & \multicolumn{5}{|c|}{$\begin{array}{l}\text { Favorableness class of the natural and } \\
\text { agricultural potential of the landscape }\end{array}$} & \multirow{2}{*}{$\min$} & \multirow{2}{*}{$\max$} & \multirow{2}{*}{$\underset{\text { type }}{\text { Communication }}$} \\
\hline & 1 & 2 & 3 & 4 & 5 & & & \\
\hline \multicolumn{9}{|c|}{ Agro-resource conditions } \\
\hline \multirow{2}{*}{$\begin{array}{l}\text { Agroclimatic } \\
\text { potential. score }\end{array}$} & $6.4-6.7$ & $6.7-7.0$ & \begin{tabular}{|l|}
$7.0-7.3$ \\
\end{tabular} & $7.3-7.6$ & 7.6-7.9 & \multirow{2}{*}{6.4} & \multirow{2}{*}{7.9} & \multirow{2}{*}{ straight } \\
\hline & $0-0.2$ & $0.2-0.4$ & $0.4-0.6$ & $0.6-0.8$ & $0.8-1.0$ & & & \\
\hline \multirow{2}{*}{$\begin{array}{l}\text { Soil bonitet. } \\
\text { score }\end{array}$} & $0-30$ & $30-40$ & $40-60$ & $60-70$ & $70-90$ & \multirow[b]{2}{*}{0} & \multirow[b]{2}{*}{90} & \multirow[b]{2}{*}{ straight } \\
\hline & $0-0.33$ & $\begin{array}{c}0.33- \\
0.44\end{array}$ & $0.44-0.67$ & $\begin{array}{c}0.67- \\
0.78 \\
\end{array}$ & $0.78-1.0$ & & & \\
\hline \multicolumn{9}{|c|}{ Geoecological conditions } \\
\hline \multirow{2}{*}{$\begin{array}{c}\text { Ecological and } \\
\text { geochemical } \\
\text { potential of soils. } \\
\text { score } \\
\end{array}$} & $0-1.5$ & $1.5-2.5$ & $2.5-3.5$ & $3.5-4.5$ & $4.5-5.0$ & \multirow[b]{2}{*}{0} & \multirow[b]{2}{*}{5.0} & \multirow[b]{2}{*}{ straight } \\
\hline & $0-0.3$ & $0.3-0.5$ & $0.5-0.7$ & $0.7-0.9$ & $0.9-1.0$ & & & \\
\hline \multirow{2}{*}{ Soil wash-off } & $4.5-4.0$ & $4.0-3.5$ & $3.5-3.0$ & $3.0-2.5$ & $2.5-2.0$ & \multirow{2}{*}{2.0} & \multirow{2}{*}{4.5} & \multirow{2}{*}{ reverse } \\
\hline & $0-0.2$ & $0.2-0.4$ & $0.4-0.6$ & $0.6-0.8$ & $0.8-1.0$ & & & \\
\hline \multirow{2}{*}{$\begin{array}{c}\text { Ecosystem } \\
\text { diversity. score }\end{array}$} & $1.0-0.8$ & $0.8-0.6$ & $0.6-0.5$ & $0.5-0.3$ & $0.3-0$ & \multirow{2}{*}{0} & \multirow{2}{*}{1.0} & \multirow{2}{*}{ reverse } \\
\hline & $0-0.2$ & $0.2-0.4$ & $0.4-0.5$ & $0.5-0.7$ & $0.7-1.0$ & & & \\
\hline \multirow{2}{*}{$\begin{array}{l}\text { Density of the } \\
\text { hydrographic } \\
\text { network. km / } \\
\text { km2 }\end{array}$} & $1.8-1.3$ & $1.3-1.0$ & $1.0-0.7$ & $0.7-0.4$ & $0.4-0.1$ & \multirow[b]{2}{*}{0.1} & \multirow[b]{2}{*}{1.8} & \multirow[b]{2}{*}{ reverse } \\
\hline & $0-0.29$ & $\begin{array}{l}0.29- \\
0.47\end{array}$ & $0.47-0.64$ & $\begin{array}{l}0.64- \\
0.82\end{array}$ & $0.82-1.0$ & & & \\
\hline \multirow{2}{*}{$\begin{array}{c}\text { Depth of } \\
\text { groundwater. m }\end{array}$} & $4.0-5.0$ & $5.0-6.0$ & $6.0-7.0$ & $7.0-8.0$ & $8.0-9.0$ & \multirow{2}{*}{4.0} & \multirow{2}{*}{9.0} & troight \\
\hline & $0-0.2$ & $0.2-0.4$ & $0.4-0.6$ & $0.6-0.8$ & $0.8-1.0$ & & & stidigit \\
\hline Erosion & $1.8-1.5$ & $1.5-1.2$ & $1.2-0.9$ & $0.9-0.6$ & $0.6-0.2$ & & & \\
\hline $\begin{array}{l}\text { potential of the } \\
\text { relief. score }\end{array}$ & $0-0.19$ & $\begin{array}{c}0.19- \\
0.38\end{array}$ & $0.38-0.56$ & $\begin{array}{c}0.56- \\
0.75 \\
\end{array}$ & $0.75-1.0$ & 0.2 & 1.8 & reverse \\
\hline $\begin{array}{r}\text { Integral indicator } \\
\text { of geoecological }\end{array}$ & $0-0.24$ & $\begin{array}{l}0.24- \\
0.42\end{array}$ & $0.42-0.61$ & $\begin{array}{l}0.61- \\
0.79\end{array}$ & $0.79-1.0$ & & & \\
\hline conditions & $\Delta=0.24$ & $\Delta=0.18$ & $\Delta=0.19$ & $\Delta=0.18$ & $\Delta=0.21$ & & & \\
\hline
\end{tabular}

Then, using the dependencies given in [16] for the soil allotments of agricultural lands of the "key" landscapes, the absolute values of the indicators characterizing them were determined, and using the dependencies (1), (2) and (4) the normalized and weighted values of the integral indicators natural and agricultural potential of soil areas were calculated. In Fig. 2, as an example, a map of the natural and agricultural potential of soil plots of agricultural land in the Svir-Oyat landscape of the Leningrad region is shown. At the final stage of work, using dependence (5) for each "key" site, an integral indicator of its naturalagricultural potential was determined, which was adopted for the corresponding species. Fig. 3 is a map of their natural and agricultural potentials, and Fig. 4 shows distribution of natural and agricultural potentials in terms of favorableness for the production of plant agricultural products.

The results of approbation of the developed methodology do not contradict the data obtained for the studied region by other researchers [17]. 


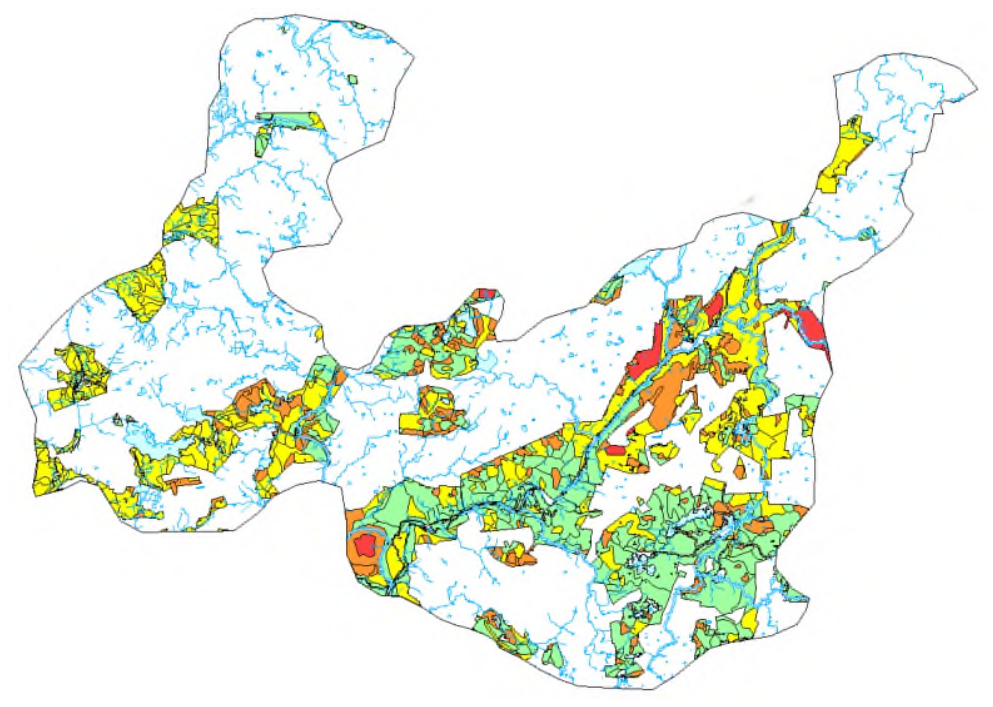

Fig. 2. Map of the natural-agrarian potential of soil allotments for agricultural land in the Svir-Oyat landscape.

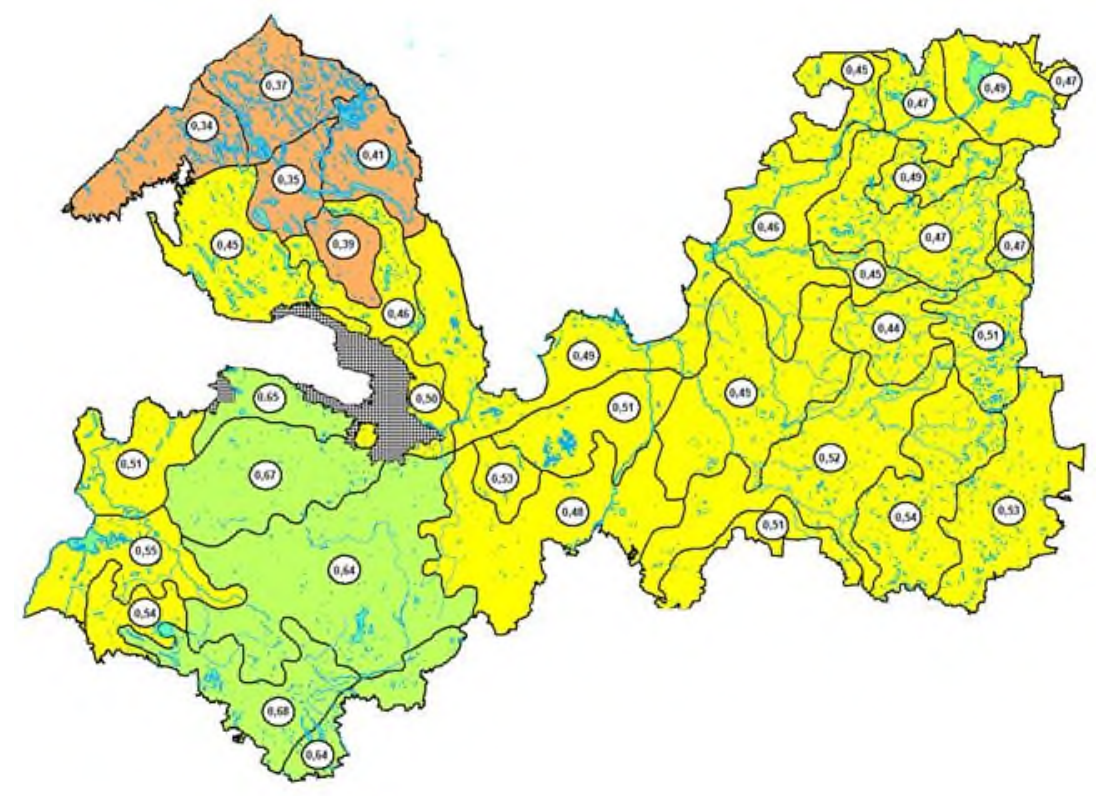

Fig. 3. Map of natural and agricultural potentials of individual landscapes of the Leningrad region. 


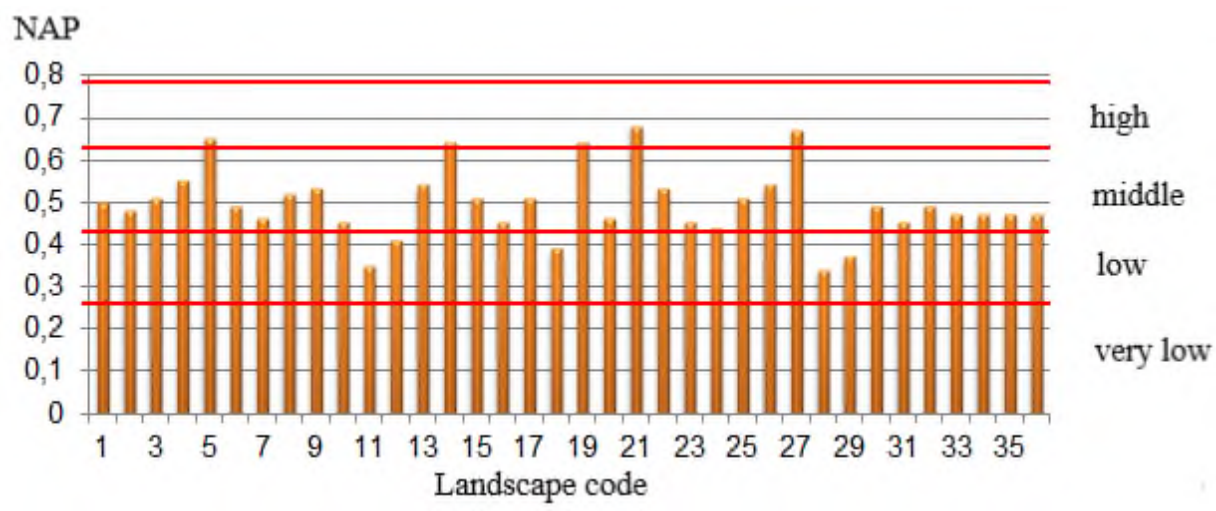

Fig. 4. Distribution of individual landscapes of the Leningrad region according to their favorable conditions for the production of vegetable agricultural products.

\section{Conclusion}

The methodology created by the authors is an effective tool for performing work on geoecological modeling of the natural-agricultural potential of landscapes during their agricultural development. It can be successfully applied in land management and spatial planning.

The introduction of the above mentioned methodology into practice will increase the efficiency of using landscapes for the production of vegetable agricultural products while maintaining their resistance to agricultural development.

\section{Acknowledgements}

The reported study was funded by RFBR according to the research project № 19-05-00683a.

\section{References}

1. N.V. Arefiev, Mining information and analytical bulletin (scientific and technical journal) 11, 303-313 (2013)

2. G.M. Beskina, Agricultural intensification systems as the basis for innovative modernization of agricultural production, 33-36 (2016)

3. A.A. Bogolyubova, Mining Institute Notes 204, 192-197 (2013)

4. A.A. Glotov, Geomatics 2, 38-41 (2014)

5. P.A. Didenko, Agrarian geography in the modern world, 67-70 (2014)

6. V.V. Dmitriev, Vestnik SPPGU 7(14), 114-129 (2014)

7. A.L. Zhelyaskov, A.P. Nesvat, Bulletin of the Orenburg State Agrarian University 1(45), 198-201 (2014)

8. N.P. Kanatieva, Scientific Bulletin of Belgorod State University 24(167), 157-161 (2013)

9. E.M. Klimina, Geography and natural resources 3, 129-132 (2003)

10. V.F. Kovyazin, V.L. Bogdanov, V.V. Garmanov, A.G. Osipov, Agrarian scientific journal 4, 14-19 (2016) 
11. V.F. Kovyazin, Mining Institute Notes 229, 98-104 (2018)

12. V.F. Kovyazin, Mining Institute Notes 204, 138-146 (2013)

13. N.V. Komov, Economy and ecology of territorial entities 1(4), 6-21 (2018)

14. M.V. Neshatayev, Mining Institute Notes 204, 203-208 (2013)

15. A.G. Osipov, Regional ecology 1-2(22), 107-114 (2004)

16. A.G. Osipov, Theory and practice of integral assessment of the suitability of natural landscape lands for agricultural and recreational development, 48 (2016)

17. P.A. Sukhanov, Scientific basis for assessing and managing the agro-resource potential of the region (on the example of the Leningrad region) (2013)

18. N.V. Khovanov, Analysis and synthesis of indicators in case of information deficit (SPBGU, 1996)

19. .G. Osipov, V.A. Pavlova, Land management, cadastre and land monitoring 8(163), 20$26(2018)$

20. Draft manual on agro-ecosystems analysis and agro-ecological zoning. LuangDrabang Province: LSUAFRP Field Report № 2004/06 6 (2004)

21. Flurbereinigung und Naturschutz in Rheinland-Pfalz. Naturschutzbund Landesverband Rheinland-Pfalz. NABU Rheinland-Pfalz (2012)

22. P. Girardin, C. Bockstaller, H.M.G. Van der Werf, Environmental Impact Assessment Review 40(2), 227-239 (2000)

23. E. Malezieux, Agronomy for Sustainable Development 32, 15-29 (2012)

24. P.P. Martins Junior, O.C. Ferreira, V.V. Vasconcelos, D.R. Jano, Economy\&EnergyAno XII 76(1), 1-18 (2010)

25. A.G. Osipov, V.V Dmitriev, S.A. Maslennikov, L.A. Plastinin, V.M. Plyusnin, Geography and Natural Resources 38(1), 12-19 (2017)

26. R.A. Poluektov, I.V. Oparina, V.V. Terleev, Russian Meteorology and Hydrology 11, 61-67 (2003)

27. V. Terleev, A. Nikonorov, I. Togo, Y. Volkova, V. Garmanov, D. Shishov, V. Pavlova, N. Semenova, W. Mirschel, Procedia Engineering 165, 1776-1783 (2016)

28. I. Dunaieva, W. Mirschel, V. Popovych, V. Pashtetsky, E. Golovastova, V. Vecherkov, A. Melnichuk, V. Terleev, A. Nikonorov, R. Ginevsky, V. Lazarev, A. Topaj, Advances in Intelligent Systems and Computing 983, 236-246 (2019)

29. A. Nikonorov, V. Badenko, V. Terleev, I. Togo, Y. Volkova, O. Skvortsova, O. Nikonova, S. Pavlov, W. Mirschel, Procedia Engineering 165, 1731-1740 (2016)

30. V.V. Terleev, A.O. Nikonorov, I. Togo, Yu.V. Volkova, R.S. Ginevsky, V.A. Lazarev, E.R. Khamzin, V.V. Garmanov, W. Mirschel, L.I. Akimov, Magazine of Civil Engineering 70(2), 84-92 (2017)

31. V. Terleev, W. Mirschel, A. Nikonorov, V. Lazarev, R. Ginevsky, A. Topaj, K. Moiseev, V. Pashtetsky, I. Dunaieva, V. Popovych, A. Melnichuk, M. Arkhipov, Advances in Intelligent Systems and Computing 983, 462-471 (2019)

32. V. Terleev, W. Mirschel, A. Nikonorov, R. Ginevsky, V. Lazarev, V. Pavlova, A. Topaj, V. Pashtetsky, I. Dunaieva, V. Popovych, A. Melnichuk, K. Layshev, Advances in Intelligent Systems and Computing 983, 449-461 (2019)

33. T. Orlova, A. Melnichuk, K. Klimenko, V. Vitvitskaya, V. Popovych, I. Dunaieva, V. Terleev, A. Nikonorov, I. Togo, Y. Volkova, W. Mirschel, V. Garmanov, IOP Conference Series: Earth and Environmental Science 90(1), 012110 (2017) 